\title{
MEMÓRIAS, IDENTIDADES, ESTRATÉGIAS E CONFLITOS: A TRAJETÓRIA DE UM MOVIMENTO SOCIOAMBIENTAL NO LITORAL DO ESTADO DO PARÁ
}

Paulo Victor Sousa Lima

\begin{abstract}
Graduando do curso de Ciências Sociais (Licenciatura e Bacharelado) pela Universidade Federal do Pará (UFPA). Bolsista do Programa Institucional de Bolsa a Iniciação Científica (PIBIC/UFPA), desenvolvendo atividades no Instituto de Filosofia e Ciências Humanas (IFCH), integrante do Núcleo de Pesquisa Ação Pública Território e Ambiente- ACTA/CNPq, sob a orientação da Prof ${ }^{a}$. Dra. Tânia Guimarães Ribeiro. E-mail: victorsousou2@gmail.com
\end{abstract}

Tânia Guimarães Ribeiro

\begin{abstract}
Doutora em Ciências Humanas (Sociologia) - Programa de PósGraduação em Sociologia e Antropologia (PPGSA) da Universidade Federal do Rio de Janeiro (2010). Mestra em Sociologia pelo Programa de Pós-Graduação em Ciências Sociais/UFPA (2000). Bacharel e Licenciada em Ciências Sociais (Sociologia) pela Faculdade de Ciências Sociais da UFRJ (1988). Atualmente é Professora Associada (Nível II) do Programa de Pós Graduação em Sociologia e Antropologia (PPGSA) e da Faculdade de Ciências Sociais da Universidade Federal do Pará (UFPA).Email:taniagr@ufpa.br
\end{abstract}

\section{RESUMO}

Esta pesquisa busca analisar um conjunto de ações coletivas que resultou na criação da Reserva Extrativista Marinha Caeté-Taperaçu, Bragança-PA. Pesquisa de caráter qualitativo auxiliada por fontes primárias e secundárias. A partir de entrevistas semiestruturadas a memória passou a ser utilizada como instrumento teórico-metodológico. A criação da reserva não resulta no fim do processo de luta por direitos sociais desta população, pelo contrário, é um processo continuado articulado em entre pequenas vitórias e luta constante, como a conquista de políticas públicas.

PALAVRAS-CHAVE: Socioambientalismo, Populações Tradicionais, Reserva Extrativista Marinha, Amazônia. 


\title{
MEMORIES, IDENTITIES, STRATEGIES AND CONFLICTS: THE PATH OF A SOCIO-ENVIRONMENTAL MOVEMENT IN THE COAST OF THE STATE OF PARÁ
}

\begin{abstract}
This research seeks to analyze a group of collective actions that resulted in the creation of the Marine Extractive Reserve Caeté-Taperaçu, Bragança-PA. Qualitative research aided by primary and secondary sources. From semistructured interviews, memory started to be used as a theoretical and methodological tool. The creation of the reserve does not result in the end of the struggle for social rights of this population, on the contrary, it is a continuous process articulated between small victories and constant struggle, such as the conquest of public policies.
\end{abstract}

KEYWORDS: Socio-environmentalism, Traditional Populations, Marine Extractive Reserve, Amazon.

\section{INTRODUÇÃO}

O objetivo deste trabalho é analisar um conjunto de ações coletivas no município de Bragança, litoral do estado do Pará, que resultou na criação da Reserva Extrativista Marinha Caeté-Taperaçu. Tendo em vista isso, traçamos dois objetivos específicos: i) identificar os atores sociais que fizeram parte dessas ações coletiva; ii) bem como mapear as estratégia utilizadas por esses grupos para alcançar o objetivo.

Esta pesquisa é de caráter qualitativo com o auxílio de fontes primárias e secundária localizados no Núcleo de Pesquisa Ação Pública, Território e Ambiente - CNPq. Utilizou-se a memória como um instrumento de metodológico, tendo em vista que o acesso às narrativas dos atores entrevistados possibilita-se a coleta de elementos (JELLI, 2001) e dessa forma reconstituir a trajetória do movimento.

Foram utilizadas um total de 9 entrevista, dentre os entrevistados estão: lideranças comunitárias e religiosas, pesquisadores e agentes do Estado. As categorias de analiticas que dão a base para análise deste conjunto de ações coletivas estão presentes na teoria dos movimentos sociais (ALONSO; COSTA; MACIEL; 2007; DIANI,1992; MELUCCI, 1980; TARROW, 2009; TILLY, 2009). Assim, a partir do olhar da sociologia sobre a memória acreditamos que a reconstrução das estratégias de um movimento social pode vir a se transformar em um instrumento de resistência para a população local (JELLI, 2001). 


\section{DESENVOLVIMENTO}

De acordo com Mario Diani (1992), são três os elementos básicos presentes em um movimento social: uma rede plural de atores, a formação de uma identidade coletiva e a presença de questões conflituosas. A seguir, serão expostas informações que demonstram que essas ações coletivas resultaram a criação de uma movimentos socioambiental (ALONSO; COSTA; MACIEL; 2007).

Os resultados estão estruturados da seguinte forma: i) uma exposição dos principais eventos identificados durante a pesquisa que repercutem em mobilizações sociais e resultam na institucionalização da REMCT em 2005; ii) Em sequência, identificamos os principais atores e organizações presentes no movimento e suas ações para compor uma identidade para essa ação coletiva; iii) Na próxima sessão, com auxílio dos seguintes conceitos: ciclos de protestos, estruturas de oportunidades políticas e repertório de ação, são analisadas as principais estratégias desses atores dentro do movimento, verificando a dinâmica dessa ação coletiva.

\section{A CRIAÇÃO DA RESERVA EXTRATIVISTA MARINHA CAETÉ-TAPERAÇU: A RECONSTITUIÇÃO DA TRAJETÓRIA DE UM MOVIMENTO}

Criada em 2005, a Reserva Extrativista Marinha Caeté compreende um extenso território destinado a proteção de área costeira e do modo de vida da população local. Oficialmente são 42 comunidades que fazem parte da Reserva. Essas comunidades estão agrupadas em pólos comunitários. Segundo dados de 2005 existem 8000 famílias vivendo nesse território. A pesca artesanal, a coleta e catação de caranguejo e o extrativismo são as principais atividades econômicas desenvolvidas. Possui todos os instrumentos previstos pelo Sistema Nacional de Unidade de Conservação, dentre eles estão a associação de mãe criada de 2005, o conselho deliberativo, o plano de manejo 2012 e o acordo de gestão 2016.

Conseguimos identificar ações e empreendimento que começaram a se desenvolver na região a partir da década de 1970. Como a construção da PA-458 e a instalação de empresas de Pesca industrial. Acreditamos que estes empreendimentos resultaram nos principais conflitos sociais no território, sobretudo em relação ao aumento do número trabalhadores na disputa pelos recursos naturais.

Verificamos que a partir desses conflitos houve uma sucessão de eventos, dentre eles a criação de associações comunitárias (Clube de Mães, associação de pescadores, entre outros), a 
chegada de grupos de pesquisas internacionais e nacionais (MADAM e a UFPA); de técnicos de órgãos do estado (IBAMA, CNPT, EMATER, entre outros); agente políticos e religiosas (vereadores, vigários locais, etc); fomentando a realização de eventos e encontros e a mobilização que tiveram como resultado a instituição da Reserva em maio de 2005.

\section{O MOVIMENTO PELA MARÉ: UMA IDENTIDADE COLETIVA PARA O POVO DO MANGUE}

A partir da análise de documentos oficiais, identificamos que essa ação coletiva possuía um nome oficial Movimento pela Maré.

De acordo com Albert Melucci (1990), a identidade coletiva é produto de uma ação social, que envolve um jogo de conflituoso entre diferentes atores, os quais estão sujeitos a manipulações. Dessa forma, observamos que o movimento foi formado por diferentes atores, dentre eles a população local, com destaque para o papel das lideranças locais; políticos locais e extra locais, (aqui podemos citar a articulação entre esses atores, a população local e lideranças religiosas para a criação de uma secretaria de pesca no município que favoreceu o movimento). Temos também a presença de pesquisadores de instituições de ensino e pesquisa, em níveis locais e internacionais, por exemplo o campus da UFPA no município e a atuação de um grupo de estudos da Alemanha, o MADAM, que teve financiamento de um projeto chamado PPG-7. Resultando em recursos para a realização de pesquisas na área como também para eventos como encontros. Temos também a presença de técnicos e pesquisadores de órgãos como a EMATER e o IBAMA através do CNPT.

\section{O REPERTÓRIO DE AÇÃO: AS ESTRATÉGIAS DO MOVIMENTO PELA MARÉ}

A partir da interpretação de Charles Tilly (2009), entendemos os repertório como um pequeno leque de opções que um movimento social incorpora como estratégias. Podendo ser entendidos como ações concretas como por exemplo, manifestações, passeatas, abaixos assinados, greves, entre outros. Para além disso, também verificamos que tais repertório podem ser entendidos como memória coletiva, uma vez que são acordos compartilhado pelos sujeito. Dessa forma, identificamos o presente repertório para o Movimento pela Maré:

1. A criação de pequenas associações que possibilitou a articulação entre os comunitários sendo também muito importante na mobilização para a coleta de assinaturas para a 
composição do abaixo-assinado;

2. O contato da população com os técnicos, pesquisadores e professores resultou um processo de ambientalização do discurso das lideranças. Isso se faz presente em outros movimentos, como no caso dos seringueiros,

3. Isso deu por meio dos encontros, reuniões, seminários e cursos

4. Também temos como instrumento, o uso das rádios locais, como meio para propagar esses discursos.

\section{AS ESTRUTURAS DE OPORTUNIDADES E OS CICLOS DE PROTESTOS: UMA CONJUNTURA FAVORÁVEL PARA A ENTRADA EM PAUTA DESSAS DEMANDAS REIVINDICATÓRIAS}

Por Estruturas de Oportunidade, entendemos que não basta apenas que sujeitos presentes no movimento saibam da existência do problema. É necessário que eles cheguem a conclusão que podem fazer algo (TARROW, 2009).

$\mathrm{Na}$ ação coletiva analisada, verificamos a presença desses elementos em diferentes níveis. Em nível internacional, verificamos a criação do PPG-7 que resultou em financiamentos para o desenvolvimento de pesquisas no território, como foi o caso do trabalho realizado pelo Grupo de Pesquisa MADAM em parceria com pesquisadores e alunos do campus da ufpa de Bragança.

Nesse cenário, verificamos a presença de ciclos de protestos a partir da repercussão da morte do seringalista Chico Mendes, dando uma maior visibilidade para o movimento socioambientalista. Resulta daí uma crescente de demandas para a criação de Unidade de Conservação pelo território nacional e consequentemente de Reservas Extrativistas Marinhas.

\section{CONSIDERAÇÕES FINAIS}

A criação da reserva não resulta no fim do processo de luta por direitos sociais desta população, pelo contrário, é um processo continuado articulado em entre pequenas vitórias e luta constante, como a conquista de políticas públicas (SILVIA, 2018; RIBEIRO e SOUSA, 2018).

Verificamos que a institucionalização da REMCT não resulta no fim do processo de

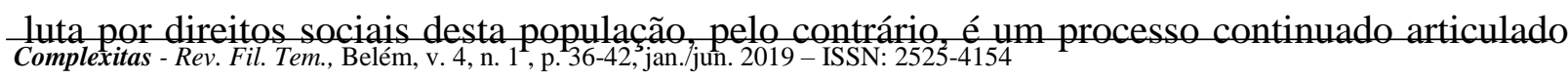


em entre pequenas vitórias e luta constante. Dessa forma a participação desses atores não se extinguiu, mas tomou outros caminhos, mobilizando setores em torno de lutas cotidianas.

Observamos a atuação de algumas lideranças comunitárias em conflitos pelas políticas públicas; na Comissão Nacional de Fortalecimento das Reservas Extrativistas Costeiras Marinhas (CONFREM); em reuniões, seminários e encontros; na renovação de representante do Conselho Deliberativo, entre outros. Assim, o resgate da memória dos atores que fizeram parte deste movimento pode se transformar em heranças para as gerações que sucederam essas lideranças. É um material que ajuda a compreender a origem dos conflitos na REMCT e as fontes de interesse associativo.

\section{REFERÊNCIAS BIBLIOGRÁFICAS}

ALONSO, Angela. COSTA, Valeriano e MARCIEL, Débora. Identidade e Estratégia na Formação do Movimento Ambientalista Brasileiro. Revista Novos Estudos 79. 2007. p. 151167

DIANI, Mario. The Conceptof Social Movement. The Sociological Review, vol. 40, no 1.1992.

JELIN, Elizabeth. Historia y Memoria Social. In:__. Los Trabajos de la Memoria. Siglo Veitntiuno: Memorias de La Represión. .España. 2001. p. 63-78

MELUCCI, Alberto. The New Social Movements: a Theoretical Approach. Social Science Information, vol. 19, n. 2,1980. p. 199- 226

RIBEIRO, Tânia G. e SOUSA, Victor L. Cidadania, renda $e$ conservação: percepções sobre uma política socioambiental na Amazônia. Nova revista Amazônica, Bragança-PA, v. 6, 2018. p. 193 - 211

SILVA, Talita. Conflitos Sociais $e$ Partilha de Políticas Públicas: a atuação da Associação dos Usuários da Resex Marinha CaetéTaperaçu, Bragança-PA. Dissertação (Mestrado em Sociologia) Programa de PósGraduação em Sociologia e Antropologia, Universidade Federal do Pará, 2018

TARROW, Sidney. O Poder em Movimento: Movimentos Sociais e Confronto Político. Editora Vozes. Petrópolis/Rio de Janeiro. 2009

TILLY, Charles. Movimentos Sociais como Política. Revista de Ciência Política, Brasília, no 3, p. 133- 160. 2010 
LIMA, P.V.S., RIBEIRO, T.G. Memórias, Identidades, Estratégias e Conflitos: A Trajetória de um Movimento Socioambiental no Litorial do Estado do Pará. Complexitas - Rev. Fil. Tem. Belém, v. 4, n. $1, \quad$ p. 36-42, jan./jun. 2019. Disponível em: http://www.periodicos.ufpa.br/index.php/complexitas/article/view/8043>. Acesso em: 30 de janeiro de 2020. 